\title{
WAGNER-JAUREGG AND FEVER THERAPY
}

\author{
by
}

\section{MAGDA WHITROW *}

Among the recipients of the Nobel prize for medicine and physiology are two psychiatrists. The first to be awarded the prize, in 1927, was the Austrian psychiatrist Julius Wagner von Jauregg for his malaria therapy for general paralysis of the insane (GPI). The second, in 1949, was the Portuguese neuro-surgeon Egas Moniz, who developed the operation of leucotomy for the treatment of severe, intractable, and progressive psychiatric disorders. The operation was often dangerous and brought with it undesirable side effects. Despite modification in the procedure, it has now been made largely obsolescent by the introduction of psychotropic drugs. Similarly, malaria therapy is no longer used for the treatment of paralytics, as this late stage of syphilis is now rarely seen because the disease is treated at an earlier stage with antibiotics. This paper examines the work that led to the award of the first psychiatric Nobel Prize to Wagner-Jauregg.

\section{WAGNER-JAUREGG'S SEARCH FOR EVIDENCE}

The idea that fever can have a curative effect on mental diseases goes back to antiquity. Hippocrates mentioned the beneficial influence of a malaria infection on epilepsy (Quartana epilepsiae vindex) and Galen cited a case of melancholy cured as a result of an attack of quartan fever. ${ }^{1}$ Sydenham and Boerhaave knew of the beneficial effect of feverish illnesses on madness. According to Neuburger, Boerhaave ${ }^{2}$ claimed that he would be the greatest of all physicians if he could produce intermittent fevers as well as treat them. Pinel ${ }^{3}$ in his Treatise on insanity referred to quartan fever as a disorder operating to produce a "permanency of recovery". In a treatise on hysteria, $P$. Briquet described two cases in which phthisis caused hysteria to disappear and another in which cholera resulted in a temporary remission of hysterical attacks. ${ }^{4}$ Esquirol in his book on mental diseases wrote that infectious diseases have a considerable effect on mental patients, indeed sometimes bringing about a complete cure. ${ }^{5}$ Maudsley referred to the "remarkable remission of the symptoms of insanity

*Magda Whitrow, BA, A.L.A., 41 Home Park Road, Wimbledon, London SW19 7HS.

\footnotetext{
${ }^{1}$ Julius Wagner-Jauregg, Lebenserinnerungen, ed. L. Schönbauer and M. Jantsch, Vienna, Springer, 1950, p. 152 (editors' comments).

${ }^{2}$ Max Neuburger, The doctrine of the healing power of nature throughout the course of time, New York, 1932, p. 56.

${ }_{3}$ Philippe Pinel, Treatise on insanity, English ed., 1806, facs. ed., New York, Hafner, 1962, p. 281.

${ }^{4}$ Pierre Briquet, Traité clinique et thérapeutique de l'hystérie, Paris, Baillière, 1859, p. 500.

5 J. E. D. Esquirol, Mental maladies; a treatise on insanity, English ed., 1845, facs. ed., New York and London, Hafner, 1965, p. 57.
} 


\section{Wagner-Jauregg and fever therapy}

which undoubtedly takes place often during the exacerbation of phthisis in a patient who has the two diseases." illness as the result of a feverish illness were quoted in the literature, particularly during the second half of the nineteenth century.

It was not this literature that aroused Julius Wagner-Jauregg's interest, but a series of observations at the Asylum of Lower Austria in Vienna, where he began work in 1883. Wagner-Jauregg had entered the field of psychiatry by chance. As he later remarked, it harmed neither him nor psychiatry. He qualified as a medical doctor at the University of Vienna in 1880. Even as a student he worked at the Institute for General and Experimental Pathology, where in 1881 he became an assistant to its head, Solomon Stricker (1834-98). From experimental pathology Wagner-Jauregg turned to internal medicine, hoping to be appointed to an assistantship in one of the two clinics for internal medicine at the Vienna General Hospital. Neither of these hopes was realized and instead he accepted the offer of an assistantship at the First Psychiatric Clinic and at the Asylum of Lower Austria, whose Director was Max Leidesdorf (1816-89). Soon after Wagner-Jauregg began work, on 28 January 1883, a woman patient contracted an attack of erysipelas and subsequently recovered from a severe mental illness. Anxious to ascertain whether the relationship between psychoses and fever was causal or purely incidental, he began a thorough search of the literature, as a result of which he wrote a lengthy article on 'The effect of feverish diseases on psychoses', published in $1887 .{ }^{7}$ In this he reviewed previous articles on the subject, and also related cases from his own experience. By this time he had gained considerable clinical experience, for soon after his appointment to the Clinic he had been promoted to the post of first assistant.

In the literature he found many observations on the effects of typhoid, cholera, intermittent fevers, acute exanthemata, and erysipelas on psychoses. Most reported instances involved typhoid, because typhoid epidemics often occurred in lunatic asylums and their effects had been documented by several observers. W. Nasse, C. M. Campbell, Gaye, R. von Krafft-Ebing, B. Oks ${ }^{8}$ and others reported that some mental patients were cured and others temporarily improved after an attack of typhoid. Wagner-Jauregg himself had observed a case of a woman admitted to his Clinic suffering from acute insanity, who several months later was taken ill with typhoid. She became quite normal for a short period, but eventually reverted to the severe insanity for which she had originally been admitted. ${ }^{9}$

\footnotetext{
${ }^{6}$ Henry Maudsley,'The causation and prevention of insanity' (1899), repr. in The origins of modern psychiatry, ed. C. Thompson, Chichester, John Wiley, 1987, p. 153.

7 Julius Wagner-Jauregg, 'Ueber die Einwirkung fieberhafter Erkrankungen auf Psychosen', Jb. Psychiat. Neurol., 1887, 7: 94-131.

${ }^{8}$ W. Nasse, 'Ueber die Beziehungen zwischen Typhus und Irresein', Allg. Z. Psychiat., 1870-71, 27: 11-42; C. M. Campbell, 'On the effects of enteric fever in the insane', J. ment. Sci., 1882-83, 28: 212-20; Gaye, 'Schilderung eines in der Irrenanstalt bei Schleswig in den Jahren 1846 und 1847 epidemisch aufgetretenen gastrischen und typhösen Fiebers', Allg. Z. Psychiat., 1852, 9: 173-99; R. von Krafft-Ebing, 'Untersuchungen über Irresein zur Zeit der Menstruation, Beobachtung XV', Arch. Psychiat., 1878, 8: 86; and B. Oks, 'Ueber die Wirkung fieberhafter Krankheiten auf Heilung von Psychosen', ibid., 1880, 10: $249-56$.

${ }^{9}$ Wagner-Jauregg, op. cit., note 7 above, pp. $98-102$.
} 
No reports were recorded of any beneficial effects of cholera. On the other hand, there were several accounts of intermittent fevers having a favourable effect on psychoses. As early as 1848 , in a thesis submitted to the University of Bonn, F. Koster had recorded seven cures and seven cases improved through malaria. ${ }^{10}$ Nasse, F. Amelung, and Oks also reported cases of cures or improvements of mental illness following attacks of malaria. ${ }^{11}$ Wagner-Jauregg himself had a case in which a patient was completely cured of epilepsy, though not entirely of his insanity, after a serious attack of intermittent fever. ${ }^{12}$ There were also reports by Köstl and Kiernan ${ }^{13}$ of the beneficial effect of smallpox, including complete cures of patients suffering from GPI. On the other hand, Wagner-Jauregg knew of four cases in which no benefit from smallpox had been observed.

Erysipelas, too, was reported to have had a curative effect on insane patients. Wagner-Jauregg described two cases in his paper of $1887 .{ }^{14}$ One patient was completely cured; in the other case the cure was only temporary, although her condition after the infection was not as bad as it had been before. A third patient, whose case was reported to Wagner-Jauregg by a colleague, completely recovered from severe paranoia after an attack of erysipelas. There are many references in the literature to cures of GPI following attacks of anthrax, and inflammation and suppuration caused by different agents. Wagner-Jauregg mentioned three of these specifically. ${ }^{15}$

All the cases reported left Wagner-Jauregg in no doubt that infectious diseases could lead to the cure of mentally ill patients. The manner in which these cures were effected varied greatly. In some cases the improvement lasted only while the patient was affected by the somatic illness, in others it continued for weeks or months; in many the symptoms of insanity disappeared with the onset of the fever, in others after the patient had recovered from it. Speculating on the mechanism of these cures, Wagner-Jauregg compared the problem to that of solving an equation with two unknown quantities: neither the changes occurring in psychoses nor the ways in which feverish illnesses acted on the nervous system were known. Any attempt at an explanation had to take into account the fact that the same agent that in one case cured a disease could produce it in another, since psychoses could be brought about by certain feverish diseases. Feverish illnesses not only had a beneficial effect on psychoses, they could also favourably affect somatic diseases, erysipelas and acute exanthemata being particularly effective in this respect. For example, acute exanthemata could result in the disappearance of some chronic skin diseases. Their action was assumed to strengthen the organism.

\footnotetext{
${ }^{10} \mathrm{~F}$. Koster, Quomodo in insaniam valeat febr. intermittens, Bonn, 1848.

${ }^{11} \mathrm{~W}$. Nasse, 'Neue Beobachtungen über den Einfluss des Wechselfiebers auf das Irresein', Allg. $Z$. Psychiat., 1864, 21: 1-46; F. Amelung, 'Bericht über die Ergebnisse des Hospitals Hofheim in statistischer und heilkundiger Beziehung vom Jahre 1847', ibid., 1849, 6: 433-4, 437-8; Oks, op. cit., note 8 above.

12 Wagner-Jauregg, op. cit., note 7 above, p. 104.

${ }^{13}$ F. Köstl, Correspondenzblatt der deutschen Gesellschaft für Psychiatrie, 1856 (as cited by WagnerJauregg; not confirmed); J. G. Kiernan, 'Variola and insanity', Zentralbl. Nervenheilk., 1884, 7: 68 (abstracted from Am. J. Neurol. Psychiat., 1883, 2: 365-72).

14 Wagner-Jauregg, op. cit., note 7 above, pp. 107-14.

${ }^{15} \mathrm{~W}$. Nasse, 'Zur Diagnose und Prognose der allgemeinen fortschreitenden Paralyse der Irren', Irrenfreund, 1870, 12: 97-115; M. Gauster, 'Die Heilung allgemeiner Paralyse', Jb. Psychiat. Neurol., 1879,
} 


\section{Wagner-Jauregg and fever therapy}

The fact that feverish conditions only sometimes resulted in cures led WagnerJauregg to enquire about the favourable circumstances. He tabulated the cases by sex and age, and by whether there was a complete cure, a significant lasting improvement, a temporary improvement, or no improvement at all. ${ }^{16}$ His tables were based on 95 cases of typhoid, 7 of typhus, 3 of cholera, 10 of intermittent fever, 22 of recurrent fever, 15 of acute exanthemata, and 11 of erysipelas, the last being the most effective. The final table listed the number of cures, lasting improvements, temporary improvements, and no improvement for the different types of psychosis, classified according to a scheme proposed by Theodor Meynert (1833-92), Professor of Psychiatry at the University of Vienna and head of the Second Psychiatric Clinic at the General Hospital. ${ }^{17}$

\section{FEVER THERAPY}

As a result of his researches, Wagner-Jauregg began to speculate whether it would be justifiable to generate fever as a therapy for psychoses. In this connection, he had in mind the vaccination experiments by Köstl and Kiernan, ${ }^{18}$ the use of blood transfusions by Leidesdorf, ${ }^{19}$ and injections of recurrent fever by A. S. Rosenblum (as reported by Oks) and by J. Motschukoffsky. ${ }^{20} \mathrm{He}$ felt that, although the evidence was then insufficient, it did justify continuing research. It would also be necessary, he thought, to collect statistics of the effect of infections occurring naturally with mentally-disturbed patients. Those diseases that harmed the patient and could not be controlled and those that could not be produced artificially had to be excluded from therapeutic use: that left intermittent fevers and erysipelas. Both could be produced artificially. The former could be treated with quinine and the latter was considered a benign disease.

Summarizing his studies, Wagner-Jauregg concluded that psychoses could be cured by fever. Consequently, it was necessary to study the conditions under which a cure took place.

Eight years elapsed before Wagner-Jauregg again wrote on the subject. His duties at the Psychiatric Clinic were arduous, particularly after its Director, Professor Leidesdorf, suffered a heart attack and Wagner-Jauregg had to take over both the Clinic's administration and Leidesdorf's lectures. Nevertheless, he pursued his researches, both experimental and theoretical, despite the inadequacy of the facilities at his disposal, and he continued his observations. During the winter of 1888/89 he inoculated several patients with a culture of streptococci originating from

1: 3-55; Doutrebente, 'Pathologie des différentes espèces de rémissions qui surviennent dans le cours de la paralysie générale progressive', Annls med. psychol., 1878, 19: 161-80, 321-41.

${ }^{16}$ Wagner-Jauregg, op. cit., note 7 above, pp. 121-4.

17 T. Meynert, in 'Bericht über den österreichisch-ungarischen Psychiatertag', Jb. Psychiat. Neurol., 1886, 6: $227-32$.

${ }^{18} \mathrm{Köstl}$, op. cit., note 13 above; Kiernan, op. cit., note 13 above.

${ }^{19}$ M. Leidesdorf, Anzeiger der kk. Gesellschaft der Aerzte in Wien, 1875 (as cited by Wagner-Jauregg; not confirmed).

${ }^{20}$ Oks, op. cit., note 8 above; Motschukoffsky, 'Experimentelle Studien über die Impfbarkeit typhöser Fieber', Zentbl. med. Wiss., 1876, 14(11): 193-4. 


\section{Magda Whitrow}

erysipelas, ${ }^{21}$ with negative results. ${ }^{22}$ After this disappointment he temporarily abandoned his experiments and only resumed them in 1890 . In the meantime, he had been appointed Professor extraordinarius at the University of Graz and Director of the Neurological and Psychiatric Clinic, where he remained until 1893, when he was called to a chair in psychiatry at the University of Vienna and the Directorship of the Neurological and Psychiatric Clinic at the County Asylum of Lower Austria.

In a lecture to the Vienna Medical Society in February $1895^{23}$ on efforts to cure insanity he recalled Professor L. Mauthner's report of a case of a long-standing progressive atrophy of the optical nerve which was cured by smallpox. ${ }^{24} \mathrm{He}$ also mentioned a personal experience at the Graz Clinic in 1892, when a 19-year-old youth had been brought in with a progressive muscular dystrophy (Dystrophia musculorum progressiva). Following a 17-day stay in the clinic he contracted "typhus abdominalis", from which he later recovered. During convalescence, it was found that the symptoms which had led to his admission to the Clinic were gradually disappearing, and he was ultimately discharged as completely cured.

Wagner-Jauregg drew attention to the achievements of "modern" bacteriology which had shed new light on the different effects of fever on psychoses. He wondered whether this could be explained by the different properties of bacterial toxins, on the one hand, or bacterial proteins, on the other. Whatever the mechanism, WagnerJauregg thought that the fact that the effect of fever on psychoses had been documented, challenged the physician to seize the chance of recovery that nature sometimes produced accidentally. There had already been attempts to effect cures by generating feverish conditions, including the use of such therapeutic procedures to bring about and maintain chronic suppuration as the seton, vesicants, and Autenrieth's ointment. The last procedure was revived with some success by Ludwig Meyer in cases of Dementia paralytica. ${ }^{25}$ Over the course of 15 years, Meyer treated 17 paralytics by rubbing the ointment on a patch of scalp that had been shaved at least twice, thus causing suppuration. Of these, eight were cured, and their case histories were described in some detail. Wagner-Jauregg was reluctant to use such a drastic procedure. Besides, he could not see why the ointment should have to be applied to the head and not to some less sensitive part of the body, if the bacterial infection were indeed the agent of the curative effect.

A little-known psychiatrist from Odessa, Alexander S. Rosenblum (1826-1902), for 20 years Chief of Staff at the Odessa Psychopathic Hospital, seems to have been the first to induce a real infectious disease in mental patients. During Wagner-Jauregg's lifetime nothing was known about him in the West, except Oks's reports on his observations and experiments on the effect of fever on psychoses. ${ }^{26}$ However, in 1943 S. J. Zakon, prompted by remarks by the American psychiatrist C. A. Neymann, succeeded not only in finding out the salient facts about Rosenblum's life, but also his

${ }^{21}$ As a result of F. Fehleisen's experiments it was possible to produce pure cultures of streptococci.

22 Wagner-Jauregg, op. cit., note 1 above, p. 157.

23 Idem, 'Psychiatrische Heilbestrebungen', Wien. klin. Wschr., 1895, 8(9): 155-9.

${ }^{24}$ L. Mauthner, 'Heilpotenzen am Sehorgan', ibid., 1894, 7: 318-19.

${ }^{25}$ L. Meyer, 'Die Behandlung der allgemeinen progressiven Paralyse (Dementia paralytica)', Berl. klin. Wschr., 1877, 14(21): 289-93.

${ }^{26}$ Oks, op. cit., note 8 above. 


\section{Wagner-Jauregg and fever therapy}

original article, published in an obscure Odessa journal, entitled 'Relation of febrile diseases to the psychoses', which Zakon translated into English. ${ }^{27}$ In it, Rosenblum analysed the literature on the subject and gave an account of the beneficial and curative effects of malaria, typhoid, and recurrent fever on psychoses from his own observations. He studied twenty-two psychiatric patients, of whom eleven were completely cured after an attack of recurrent fever and three partially cured; the condition of eight remained unchanged. However, in this article Rosenblum did not say that he had induced the fever, although this is clear from his communication to Oks, probably because he feared that in the prevailing political circumstances in Russia this would have met with severe disapproval. From a reading of Oks's paper Wagner-Jauregg originally considered Rosenblum's experiments to have been the first successful attempts at using feverish illnesses to cure mental illness, and he believed that a report by the bacteriologist Motschutkoffsky from Odessa on recurrent fevers being caused by inoculations ${ }^{28}$ might have referred to the same experiments. Later he voiced his doubts as to whether the fevers were induced for psychiatric purposes, wondering if this had been done to test the transference of recurrent fevers instead. ${ }^{29}$ However, he must have finally reverted to his original view, for he assured V. E. Gonda, whom he met at the International Neurological Congress in London in 1935, that he gave Rosenblum full credit for his daring undertaking. ${ }^{30}$

\section{EXPERIMENTS WITH TUBERCULIN}

Not long after Wagner-Jauregg had his disappointing results with the streptococci inoculations, one of his colleagues, Theodor Escherich (1857-1911), the well-known paediatrician and the first to describe the Bacillus coli communis, brought from Berlin a few bottles of tuberculin. One of these he gave to Wagner-Jauregg, who was looking for a safe method of continuing his tests and, as he had written in his 1895 paper, ${ }^{31}$ thought that in tuberculin he had found just that. It provided a method for producing artificially the effects of bacterial infection, above all fever, without the dangers of a real bacterial infection. During the winter of $1890 / 91$ he treated a number of patients with favourable results, two of his patients being quickly cured of their psychoses. Nevertheless, he abandoned his experiments for a time. The reason he gave was that cures produced with therapeutic tuberculin were very slow. At the Graz Clinic only acute cases were admitted and patients kept only for a short time, so that it was not possible for him to observe the results of the treatment. On the other hand, in his Memoirs $^{32}$ he confessed that, despite the favourable results he had had with tuberculin, he discontinued his experiments because of alarming reports that the dangers of the therapeutic use of tuberculin had been underestimated and there had even been some deaths as a result.

${ }^{27}$ A. S. Rosenblum, 'Relation of febrile diseases to the psychoses', Arch. Derm. Syph., 1943, 48: 52-8, transl. from Trudi vrach. Odessk. g. boln., 1876-77, vol. 2, pt. B, by S. J. Zakon, with comments by C. A. Neymann.

${ }_{28}$ Motschutkoffsky, op. cit., note 20 above.

29 Julius Wagner-Jauregg, Fieber- und Infektionstherapie, Wien, Weidmann, 1936, pp. 74-5.

30 V. E. Gonda, "Wagner-Jauregg and the "priority" of producing artificial fever for treatment of general paresis', Am. J. Psychiat. Neurol., 1957, 114: 561-2.

31 Wagner-Jauregg, op. cit., note 23 above.

32 Idem, op. cit., note 1 above. 


\section{Magda Whitrow}

Robert Koch (1843-1910) had claimed that the substance which he had discovered had the power to prevent the growth of tubercle bacilli, and that he had had excellent results in clinical trials. However, mounting evidence of the drug's toxicityparticularly Rudolf Virchow's post-mortem demonstrations of intense local inflammatory reactions in treated cases ${ }^{33}$-intensified doubts about the new remedy. Although Koch had cautioned that only early cases responded at all well, the attack upon him rapidly gained momentum. The Gazette de Bruxelles accused him of publishing a "most audacious and hopeful report" and in July 1891 the Second Congress on Tuberculosis in Paris decided that tuberculin was of very doubtful value. ${ }^{34}$ Within twelve months of its introduction, tuberculin passed into a period of profound disrepute. A very vivid description of its over-enthusiastic reception and the dire consequences was given by Theodor Brugsch in his autobiography. ${ }^{35}$ When he was about nine years old he was often taken on walks past a building that was being converted into a coffee house and restaurant. Suddenly it became a tuberculosis sanatorium. No sooner had it been equipped and filled with patients, than he saw hearse after hearse stopping outside the building to carry away the dead.

Wagner-Jauregg's two different explanations for discontinuing his tuberculin experiments may well have been due to his reluctance to add his voice to the accusations levelled against Koch.

In 1893 Wagner-Jauregg was appointed to a chair in psychiatry at the University of Vienna and Director of the First Psychiatric Clinic at the County Lunatic Asylum of Lower Austria, where he had begun his career. He succeeded Richard von KrafftEbing (1840-1902), who was taking over Meynert's post as the Director of the Second Psychiatric Clinic at the General Hospital, where the variety of patients was far greater. Soon after Wagner-Jauregg began work at the First Clinic, one of his assistants, Dr Ernst Boeck, wished to test the curative effect of feverish infectious diseases on insanity by injecting bacterial proteins. However, Wagner-Jauregg advised the use of tuberculin instead. It was easily obtainable and he felt that by then sufficient experience had been gained of safe dosages to prevent adverse effects. Consequently, Boeck continued the experiments which Wagner-Jauregg had initiated at Graz, of injecting tuberculin into psychiatric patients. He reported on these in $1895 .^{36} 33$ patients were treated, but there were few remissions. Only one among those treated was suffering from GPI. Boeck also injected eight patients with dead cultures of Bacillus pyocyaneus, but again the results were disappointing. In this case, unlike that of tuberculin, it was not possible to increase the initial dose.

In a preliminary report on the experiments carried out in collaboration with Boeck, ${ }^{37}$ Wagner-Jauregg was the more optimistic of the two about the prospects of the treatment. He illustrated the astonishing improvement that could occur with the case of one of his patients who was visited by her sister on the day after the injection.

\footnotetext{
${ }^{33} \mathrm{R}$. Virchow, 'On the action of Koch's remedy upon internal organs in tuberculosis', Lancet, 1891, i: $130-2$.

34 A. G. Macintyre, 'Tuberculin therapy', Oxford Medical School Gaz., 1954, 6: 146-52.

35 Theodor Brugsch, Arzt seit fünf Jahrzehnten, Berlin, Rütten \& Loening, 1957.

${ }^{36}$ E. Boeck, 'Versuche über die Einwirkung künstlich erzeugten Fiebers bei Psychosen', Jb. Psychiat. Neurol., 1895, 14: 199-268.

37 Wagner-Jauregg, op. cit., note 23 above.
} 
The visitor approached one of the doctors with the question "What have you done with my sister? she has suddenly become intelligent". In the same lecture, WagnerJauregg considered the theoretical problem of whether the fever alone had a curative effect, in which case it would not matter whether tuberculin or some other bacterial protein was injected. If, however, the curative effect depended on the specific characteristics of the bacterial proteins, then a case which failed to respond to treatment with tuberculin might be favourably affected by another bacterial protein. He thought that Boeck had taken the first step in this direction by using dead cultures of Bacillus pyocyaneus. Wagner-Jauregg warned his listeners that, although there had been some favourable results, there had also been failures. Nevertheless, he concluded that "we cannot be reproached for using a procedure which is irrational. We have listened to nature; we have attempted to imitate the method by which nature itself produces cures." 38

Wagner-Jauregg continued his experiments with tuberculin after Boeck left the Clinic to take up another appointment. He treated several patients suffering from GPI, who responded favourably. From then on he concentrated his efforts on patients afflicted by that illness. In the postscript to the 1895 paper, published in the collection of his papers, ${ }^{39}$ he stated as the reason for this decision that it had been noticeable that among those who had benefited from the tuberculin treatment, there were many more paralytics than patients suffering from other forms of mental illness. Moreover, GPI was thought to be incurable and consequently it could not be said that the patient might have recovered without treatment. Of course, although the clinical diagnosis of GPI was relatively certain, it was not completely reliable until the development of the Wassermann test in 1906. During the years 1900 and 1901 Wagner-Jauregg treated 69 cases of patients suffering from GPI with tuberculin, and compared them with 69 untreated cases. ${ }^{40} \mathrm{He}$ worked with dosages of $1 \mathrm{mg}$ to $10 \mathrm{mg}$. After three years he arranged for his assistant Dr A. Pilcz to publish the results. ${ }^{4}$ They clearly showed that there were more remissions among the patients who had been treated than among those not subjected to treatment. An interesting feature of the trial was that the treatment was most beneficial to those whose reaction to the tuberculin was strongest.

Wagner-Jauregg gave an account of his experiments at the Sixteenth International Medical Congress in Budapest in $1909 .{ }^{42} \mathrm{He}$ had chosen patients in the early stages of paralysis and combined the tuberculin therapy with a treatment with mercury (the standard treatment for syphilis) and iodine, since it had been more-or-less established by 1902 that GPI was of syphilitic origin. ${ }^{43}$ The results of the combined therapy were favourable, many patients making a good recovery and often being able to resume

\footnotetext{
38 Ibid., p. 159.

39 Idem, op. cit., note 29 above.

40 Idem, op. cit., note 1 above, p. 160.

41 A. Pilcz, 'Ueber Heilversuche an Paralytikern', Jb. Psychiat. Neurol., 1905, 25: 141-67.

42 Julius Wagner-Jauregg, 'Ueber die Behandlung der progressiven Paralyse', Wien. med. Wschr., 1909, 59(37): 2124-7.

${ }^{43}$ In 1893 J. A. Fourrier, in Les affections parasyphilitiques (Paris, Rueff, 1894), had proposed that there was a causal relation between tabes and GPI with syphilis. Actually, as early as 1857 F. Esmarch and W. Jessen, in Allg. Z. Psychiat., 1857, 14: 20-36, suggested a connection between GPI and syphilis.
} 


\section{Magda Whitrow}

their professional activities. Among patients who did not respond to this treatment, a repetition of the therapy often brought favourable results. Forestalling the criticism that there were only remissions but no cure, he argued that this was of little importance because in no field of pathology did the possibility of a recurrence of the illness prevent one from speaking of a cure. In his Memoirs, recalling the occasion, ${ }^{44}$ he wrote with some irony that the success of his lecture was "not overwhelming". In fact, he encountered general scepticism and there was no discussion. Nevertheless, in Vienna, at least, the number of unexpected cures of patients suffering from GPI was beginning to attract attention. Wagner-Jauregg also received support from Ernst Meyer, who reported encouraging results after treating 20 paralytic patients with tuberculin and antisyphilitic medication. ${ }^{45}$

A further trial involving 86 patients was made using a combination of tuberculin and mercury and iodine treatment, on which Pilcz reported in $1911^{46}$ and WagnerJauregg in $1912 .{ }^{47}$ It was found that, of 86 patients, 23 could be said to be cured and were able to return to their work; 9, although intellectually weak and unable to resume their occupations, were able to return to their families and lead a reasonably normal life; in 20 cases, although there was no essential improvement, the progress of the paralysis was halted; and in the remaining 34 cases the treatment had no effect, the few remissions being short-lived. The patients involved in this trial were in an early stage of paralysis. Because the successive treatments with tuberculin followed by antiluetic agents took some time, a method of applying each on alternate days was adopted.

Two years later Wagner-Jauregg summed up the results of the tuberculin treatment in conjunction with antiluetic medication. ${ }^{48} \mathrm{He}$ was very critical of the author of the chapter on progressive paralysis in Aschaffenburg's Handbuch der Psychiatrie, who did not even mention the tuberculin treatment; but welcomed the approving papers by E. Meyer and Friedländer, ${ }^{49}$ who both quoted favourable results from the treatment. There were also a few other reports on the beneficial effects of the therapy. In describing the methodology of the experiments, Wagner-Jauregg wrote that he much regretted not being able to carry out comparative trials. His hope that these might be undertaken at the asylums, which had large numbers of patients who could be observed for long periods, had not been fulfilled. He himself was no longer able to carry out such trials since in 1902, on succeeding Krafft-Ebing, he had exchanged the Clinic at the Asylum for the more important and prestigious Clinic at the General Hospital, where patients were seldom kept for any length of time. The former had no special department for nervous diseases, whereas at the General Hospital there was a

\footnotetext{
44 Wagner-Jauregg, op. cit., note 1 above, p. 161.

45 E. Meyer, 'Zur Behandlung der progressiven Paralyse', Münch. med. Wschr., 1912, no. 49, p. 2704.

46 A. Pilcz, 'Zur Prognose und Behandlung der progressiven Paralyse', Z. ges. Neurol. Psychiat., 191 1, 4(4), abstract ibid., 3: 94-95.

47 Julius Wagner-Jauregg, 'Zur Behandlung der progressiven Paralyse mit Bakterientoxinen', Wien. klin. Wschr., 1912, 25(1): 61-3.

48 Idem, 'Die Tuberkulin-Quecksilberbehandlung der progressiven Paralyse', Therap. Monatshefte, 1914, 28: $1-8$.

${ }^{49}$ Meyer, op. cit., note 45 above; and Friedländer, 'Ueber die Einwirkung fieberhafter Prozesse auf metaluetische Erkrankungen des Zentralnervensystems', Münch. med. Wschr., 1912, no. 38, pp. $2038-40$.
} 


\section{Wagner-Jauregg and fever therapy}

Clinic and an Out-patient Department for Nervous Diseases and consequently a greater variety of cases.

Around 1910, Wagner-Jauregg had decided to experiment with dead cultures of staphylococci using polyvalent preparations made from at least six cultures. He reported on these in $1913 .{ }^{50} \mathrm{He}$ had treated 39 men suffering from GPI. Of these, 23 experienced a distinct remission. Although in 16 the remission was temporary, with the remaining seven it had already lasted for two years. Most of the patients treated suffered from the manic type of paralysis, but Wagner-Jauregg could not say at the time whether such patients had a better chance of a cure. In the collection of his papers on fever therapy published in $1936,{ }^{51}$ there is a postscript to this paper, the last that appeared before he embarked on his malaria therapy, in which he wrote that he had still been dissatisfied with the results of the treatment that he had pioneered. Although there were a considerable number of complete remissions, they only lasted in a minority of cases; the majority of patients relapsed, even though they were able to resume their occupation for a year or two. The best results occurred when some feverish illness intervened. This circumstance suggested to him to produce in paralytics a real infectious disease, the course of which could be controlled, and which would not endanger the environment.

\section{MALARIA THERAPY}

As early as 1887 , Wagner-Jauregg had suggested the artificial production of tertian malaria. A chance event caused him to take up the idea, and this led to the beginning of malaria therapy in June 1917. There is a vivid account of this event in his Memoirs. ${ }^{52}$ One of his colleagues, Dr Alfred Fuchs, reported to him that a soldier who had been admitted to hospital on his return from the Macedonian front with a slight injury to his nerves, was suffering attacks of fever accompanied by shivering fits of the tertian type, and asked whether he ought to give him quinine. Immediately, the idea occurred to Wagner-Jauregg to inoculate GPI sufferers with the blood of this malaria patient. "No", he replied to his colleague, and he explained what he intended to do. So on 14 June 1917 he took blood from the vein of the soldier during an attack of fever and inoculated two paralytics with it. Then he became worried lest there were some anopheles mosquitoes in the grounds of the Clinic and the malaria might spread. He got one of the neurotic patients who was still able to carry out simple tasks to catch as many gnats as he could and bring them in for examination. To his great relief, there were no anopheles mosquitoes among them. Thus encouraged, he took blood twice more from the malaria patient and injected it subcutaneously under the skin of the back of paralytic patients. From the blood of the GPI patients who contracted malaria in this way, three more patients were infected by subcutaneous injection, and with the blood of one of this group two more patients were injected. In all these cases the presence of tertian plasmodium was microscopically confirmed in the blood.

\footnotetext{
50 Julius Wagner-Jauregg, 'Ueber Behandlung der progressiven Paralyse mit Staphylokokkenvakzine', Wien. med. Wschr., 1913, 63(39): 2556-8.

51 Idem, op. cit., note 29 above, pp. 115-16.

52 Idem, op. cit., note 1 above, pp. 163 et seq.
} 


\section{Magda Whitrow}

At the invitation of the editor of the Psychiatrisch-neurologische Wochenschrift Wagner-Jauregg gave a detailed account of the case histories of the first nine patients treated with malaria. ${ }^{53}$ Apart from one patient who died while Wagner-Jauregg was away on a scientific medical commission to the Isonzo front, and two who had to be sent to the asylum after a few months, the remaining six all showed considerable improvement, but all except two eventually suffered relapses. Of the latter, one was a tram conductor, 34 years old, who had joined the army in 1915. He was admitted to the Clinic as insane early in June 1917. After eleven attacks of fever he was treated with quinine. His improvement was slow but steady. He recovered, and a little more than a year after admission was sent back to his regiment for auxiliary duties at his own request. The other was a clerical worker, 39 years old, suffering from the manic type of general paralysis. After he had had ten attacks of fever, he was treated with quinine and later with Salvarsan. He recovered completely and was able to resume his work.

Of the remaining four who were discharged as cured and able to resume their work, one, a woman cleaner, had to be re-admitted the following year. Another, a railway worker, who left the Clinic about a year after the treatment, later committed suicide in a state of depression. In the third case, that of a sergeant-major admitted in the manic state of paralysis, the remission only lasted for a few months. The story of the fourth, actually the first to be treated, is extraordinary. The patient was a 37-year-old actor who was admitted to the Clinic suffering from loss of memory and epileptic fits due to suspected paralysis. As a result of the malaria treatment he improved so much that within two months he was able to give performances at social evenings for patients. He was discharged at the end of the year and was able to resume his profession. In a postscript to the paper, added in $1936,{ }^{54}$ Wagner-Jauregg recounted how some months later he received an enquiry from Dr Raphael Weichbrodt of the Frankfurt-am-Main Asylum regarding this patient, who had evidently had a relapse. His wife had told Dr Weichbrodt of the miraculously successful treatment that her husband had received in Vienna, and, of course, Dr Weichbrodt wanted to know more about it. When Wagner-Jauregg wrote to him about the malaria therapy (he had not published anything at that time), Weichbrodt inoculated four of his paralytic patients with malaria and had great success with two of them. He later used inoculations with spirilla causing recurrent fever.

In all the cases that Wagner-Jauregg treated with malaria, he administered, after seven to twelve attacks of fever, $1 \mathrm{~g}$ of quinine bisulphate a day for three days and then $0.5 \mathrm{~g}$ daily for fourteen days. In each case the fever ceased after the first few doses. In addition, the patients received three intravenous injections of Neosalvarsan at weekly intervals. It was noticed that in most cases the fever attacks turned into the quotidian type. Wagner-Jauregg wished to continue his trials of malaria therapy. Since he had no malaria patients at his Clinic, he approached a specialist in internal medicine, who was in charge of a department in a military hospital where there were many malaria patients, to let him have blood from a confirmed case of tertian

\footnotetext{
${ }^{53}$ Idem, 'Ueber die Einwirkung der Malaria auf die progressive Paralyse', Psychiat.-neurol. Wschr., 1918, no. $21 / 22$, pp. $132-4 ; 1919$, no. 39/40, pp. 251-5.

54 Idem, op. cit., note 29 above, p. 135.
} 


\section{Wagner-Jauregg and fever therapy}

malaria. ${ }^{55}$ Unfortunately, he omitted to examine microscopically the blood received (he feared that any delay might affect the infectious nature of the blood) and he immediately injected one paralytic patient with it. When this patient's temperature began to rise, he took blood from him and injected three other paralytic patients with it. The first patient became seriously ill; the fever did not cease despite large doses of quinine. The blood test showed that nearly all his blood cells were covered with plasmodia. The number of red corpuscles decreased frighteningly, and the white cells disappeared altogether. It was clearly a malignant type of malaria tropica. The patient died after 31 days, as did two others who had been injected. The fourth survived after large doses of quinine and Neosalvarsan were administered for $\mathbf{4 5}$ days; his paralysis was cured completely and lastingly. Nevertheless, the fate that befell the other patients discouraged Wagner-Jauregg and he did not feel able to continue his trials with malaria, particularly as some authorities claimed to achieve better results with injections of spirilla causing recurrent fever.

It was a year before he resumed his trials, when the bacteriologist Professor $\mathbf{R}$. Doerr (1871-1952) came to his aid. He had found a case of confirmed tertian malaria. The patient lived in an area where autochthonous cases of malaria occasionally occurred. Often there were malaria cases among the crew of the steamers that brought goods to Vienna from Hungary, Serbia, Romania, and Bulgaria. The inhabitants on both banks of the Danube sometimes became infected if they were bitten by an anopheles mosquito that had previously attacked one of the sailors. Although Doerr was not concerned with the fate of the paralytic patients, he needed to make experiments with malaria vaccination, and at his request three paralytic patients were injected with different concentrations of the blood from the malaria patient. In his Memoirs Wagner-Jauregg reported that the "results of the experiments did not come up to Professor Doerr's expectations", ${ }^{56}$ because it was not the patient who had received the strongest concentration of the blood who developed malaria but the one who was given one of medium strength. Wagner-Jauregg decided to make no more experiments with different concentrations, particularly because in the meantime Doerr had left Vienna to take up an appointment in Basle. From the paralytic patient who received blood in September 1919 from Doerr's malaria patient blood was taken to vaccinate further paralytic patients in a continual passage from one to another. From this time the malaria therapy of progressive paralysis was continued at the Vienna Psychiatric Clinic on a large scale without interruption. All patients suffering from GPI, both men and women, and also those suffering from tabes were treated. More and more patients who had come to the Clinic as hopeless cases were able to return to their families and their work, and more and more sufferers came to the Clinic to be treated.

It so happened that Wagner-Jauregg was chosen as a representative of Austria on the Council of the German Psychiatric Association. In the autumn of 1920 its Annual Conference took place in Hamburg, and among the speakers was a physician from the Hamburg Municipal Asylum, who reported on behalf of three colleagues on the

${ }^{55}$ Idem, op. cit., note 1 above, pp. 163-5.

${ }^{56}$ Ibid., p. 166. 


\section{Magda Whitrow}

results they had achieved in an attempt to treat GPI by inoculation with tertian and tropical malaria. Only at the end of this communication did the speaker mention that Wagner-Jauregg had made similar experiments. When the lecture was published in the Münchner Medizinische Wochenschrift two months after the meeting, ${ }^{57}$ WagnerJauregg's priority was acknowledged. In his reply, Wagner-Jauregg stressed that he had carried out the first inoculations with malaria in 1917, but had discontinued them for one year to await results. (In fact, as mentioned above, he had interrupted his experiments for a time because he became discouraged as a result of the disastrous consequences of the use of malaria tropica instead of tertiana.) After resuming his treatments, Wagner-Jauregg said, he had achieved many more cures than the three workers mentioned. He was, however, able to warn them against the use of malaria tropica.

In a lecture in February $1921^{58}$ Wagner-Jauregg said that more than 150 cases had received the malaria treatment, and more than a dozen had been able to resume work. In some cases the remission had lasted for more than three years. Later that year ${ }^{59}$ he reported that more than 200 patients had been treated, of whom 50 had been able to return to work.

A more detailed account of the treatments and the results achieved was given by J. Gerstmann, one of the assistants at Wagner-Jauregg's Clinic, in two articles published in 1920 and 1922 and in book form in $1925 .^{60}$ By that time the number of paralytics treated exceeded 1,000. Although at first very advanced cases of paralysis were not subjected to the malaria therapy, during the last two years under review all paralytics admitted to the Clinic were so treated. However, in the statistical analysis only fully or partially successful cases that had been observed for two years or more were included, i.e. 400 cases. Over 60 per cent of the patients experienced remissions of different degrees.

Gerstmann related the fascinating case histories of five patients who made a complete recovery. They were middle-aged men, three in clerical occupations, one an upholsterer, and one a driver. They were all brought to the Clinic with various symptoms of progressive paralysis and all had contracted a syphilitic infection several years previously. They showed impairment of mental functions and speech, besides such symptoms as megalomania, mania, euphoria, and paralytic seizures. They were treated with tertian malaria, the onset of a remission varying greatly from patient to patient. It was often some time before an improvement was noted. In one case it took two months, in another the patient was returned to the asylum as he showed no sign of recovery, but his condition gradually improved so much that he was able to take up his previous post after six months. The other patients recovered gradually after the attacks of fever.

\footnotetext{
${ }^{57}$ P. Mühlens, W. Weygandt, and W. Kirschbaum, 'Die Behandlung der Paralyse mit Malaria- und Rekurrensfieber', Münch. med. Wschr., 1920, 67: 831-3.

58 Julius Wagner-Jauregg, 'Die Behandlung der progressiven Paralyse und Tabes', Wien. med. Wschr., 1921, 71(25): 1105-9; (27): 1209-15.

${ }^{59}$ Idem, 'The treatment of general paresis by inoculation of malaria', J. nerv. ment. Dis., 1922, 55: 369-75.

60 J. Gerstmann, 'Ueber die Einwirkung der Malaria tertiana auf die progressive Paralyse', Z. ges. Neurol. Psychiat., 1920, 60: 328-59; 1922, 74: 242-58; Die Malariabehandlung der progressiven Paralyse, Wien, Springer, 1925.
} 


\section{Wagner-Jauregg and fever therapy}

Needless to say, early cases of paralysis had a much higher chance of recovery than those who had suffered from the disease for some years. In cases of long standing, it was to be expected that the GPI had caused irreversible changes in the nervous system. The two symptoms that had most regularly improved after malaria therapy were defects of speech and writing. It was remarkable how patients whose writing was jittery and unco-ordinated reverted to normality in this respect. Patients who had suffered paralytic seizures also responded well to the treatment. On the other hand, even in cases of complete recovery, pupil reactions did not return to normal. Moreover, it was usually some time before the Wassermann reaction of the serum and spinal fluid became negative.

In view of the favourable results obtained in early cases of paralysis and the fact that it was known who might succumb to the disease-those who, having contracted syphilis some time previously, still had positive Wassermann reactions-it seemed advisable to treat these patients before the onset of paralysis. One of WagnerJauregg's assistants, Dr Bernhard Dattner, suggested that this ought to be done, but there were no patients of this kind at the Clinic. ${ }^{61}$ They were to be found at the Clinic for Syphilis and therefore Wagner-Jauregg sent Dattner to Professor Josef Kyrle there with this suggestion. Kyrle was at first unwilling for them to be treated. He maintained that it was one thing to inoculate with malaria a paralytic who was a hopeless case and quite another to treat a seemingly healthy person in this way just because his reaction was positive. However, a few weeks later, Kyrle told WagnerJauregg that he had tried the treatment and it had worked. He reported on his work at a joint meeting of the German Society for Psychiatry and the Society of German Neurologists and Venereologists in September $1924 .{ }^{62}$ Several psychiatrists joined in the discussion and reported favourably on their experiences with malaria therapy: M. Nonne, W. Weygandt and W. Kirschbaum of Hamburg, G. Mingazzini of Rome, E. Sträussler and G. Koskinas of Prague, Bering of Essen, Lampar of Graz, and C. Mayer of Innsbruck. Gerstmann gave fuller details of results obtained at the Vienna Clinic. Wagner-Jauregg described experiments to prove whether, and under what conditions, induced malaria could be transmitted by the anopheles mosquito. They were carried out by the Italian bacteriologist Dr G. Barzilai-Vivaldi and were performed at Wagner-Jauregg's Clinic with the assistance of Dr O. Kauders, between June and August 1924. These complicated experiments used a large number of Anopheles maculi pennis, which had been bred in Rome. The insects were distributed in cages covered with netting, through which they were able to bite a number of paralytic patients who were suffering from malaria fever at different stages of severity. Later six paralytic patients who had not yet been subjected to the malaria therapy were brought into the same room. They too were exposed to bites from these mosquitoes so that they should be infected with malaria. Altogether they suffered 127 bites. After three weeks not one of these six patients had been infected. They were later subjected to the malaria therapy which followed its usual course. The experiments proved that induced malaria could not be transmitted by anopheles bite.

${ }^{61}$ Wagner-Jauregg, op. cit., note 1 above, p. 168.

62 '88. Versammlung Deutscher Naturforscher und Aerzte in Innsbruck', Zentbl. ges. Neurol. Psychiat., 1925, 39: 464-80; G. Barzilai-Vivaldi and O. Kauders, Wien. klin. Wschr., 1924, 37: 1055-7. 
MALARIA THERAPY WORLD-WIDE

It was not long after Wagner-Jauregg published details of his malaria therapy that the treatment was introduced at the Hamburg Asylum and the Hamburg Clinic for Nervous Diseases. During 1920 several other institutions in Germany followed suit. By 1921 the treatment had been introduced in The Netherlands and South America; by 1922 it had spread to Britain, Italy, and Czechoslovakia and by 1923 its use was reported in the United States, Russia, Denmark, and France. During the following years, 1924, 1925, and 1926, there were many reports on the use of malaria therapy at institutions all over the world. In the Index Catalogue to the Surgeon General's Library (4th series, vol. 8), published in Washington in 1929, there are three closely-printed columns listing papers published in the mid-1920s on malaria therapy in the treatment of GPI. Most of these articles leave no doubt that Wagner-Jauregg's discovery was welcomed and appreciated. The descriptions used were a "therapeutic noble deed", a "distinct advance in treatment", the "right way to treat a hopeless disease", "unquestionably a method of value", the "best treatment available". A. Hoche in Switzerland thought it a duty to use the malaria treatment. ${ }^{63}$ As early as 1923 an editorial in the American Journal of Psychiatry urged that observations be made on the effects of malarial infection on the progress of paresis: "It may be that every large hospital for mental disorders may have to maintain one or more malarial patients as source of infectious material."64 In Britain, too, there were favourable comments. An editorial in Nature urged that every endeavour should be made to investigate and perfect a method that offered hope of improvement. ${ }^{65}$ Warrington Yorke, commenting on results achieved at a number of mental hospitals in the Liverpool area, called them remarkable. ${ }^{66}$ The reception of the therapy was particularly enthusiastic in the United States, where it was adopted in many institutions, including the New York State Psychiatric Institute, and asylums at Madison (Wisconsin), Indianapolis, and Harrisburg.

The results were broadly consistent. Generally, the success rate was about 30 per cent full remission and 20 per cent partial remission. Most reports agreed that the Wassermann reaction of the serum and spinal fluid remained positive for a considerable time and did not always revert to normal. In such cases, Wagner-Jauregg recommended, the malaria treatment should be repeated. ${ }^{67}$

The mode of infecting the patient varied from country to country. In Britain, instead of producing the disease by the inoculation of malaria blood, it was induced by the bite of infected mosquitoes. Three American researchers also reported better results when the patient was infected directly by a mosquito, rather than inoculated with infected blood. ${ }^{68}$ Wagner-Jauregg was not in favour of the former method, which involved true, not induced malaria. He thought that the latter responded most

${ }^{63}$ A. Hoche, 'Die Behandlung der progressiven Paralyse', Schweiz. med. Wschr., 1925, 6: 133-5.

64 'Editorial', Amer. J. Psychiat., 1923, 79: 721-3.

65 'The malarial treatment of general paralysis', Nature, 1924, 114: 164-5.

66 Warrington Yorke, 'The malarial treatment of general paresis', ibid., p. 615.

67 Julius Wagner-Jauregg, in Verhandlungen der deutschen Gesellschaft für Innere Medizin, 38. Congress Wiesbaden, April 1926, pp. 34-62.

${ }^{68}$ E. Kusch, D. F. Milam, and W. K. Stratman-Thomas, 'General paresis treated by mosquito inoculated tertian malaria', Amer. J. Psychiat., 1936, 93: 619. 


\section{Wagner-Jauregg and fever therapy}

readily to treatment with quinine and did not recur afterwards. He recommended the use of blood that was free from trypanosome gametes; this offered much better protection for the environment. ${ }^{69}$

The Nature editorial warned of the risk of the parasite being conveyed to other persons by the mosquito and referred to the letter of the Board of Control to asylum superintendents recommending a number of precautions. ${ }^{70}$ Some authors warned of the high mortality of the treatment and suggested great care in the choice of patients fit to be subjected to it. W. M. McAlister claimed that, although remission of considerable duration could be produced, complete cure was outside the scope of the method. $^{71}$

Some German researchers used the African recurrent fever in place of malaria and obtained good results. Wagner-Jauregg, speaking of the differences between these two types of treatment, said that recurrent fever caused an immunity, the duration of which could not be gauged, and this treatment, unlike malaria, could therefore not be repeated. Moreover, it was impossible to stop the fever attacks because they did not respond to treatment with quinine. At Wagner-Jauregg's Clinic a comparative trial was made for four months during the spring and summer of 1925 in which one patient was treated with malaria, the next with recurrent fever, and so on. Of 33 patients treated with maleria, 14 recovered from general paralysis and were able to return to their professions, and 10 showed incomplete remissions; whereas of the 33 treated with recurrent fever, only 6 recovered and 9 showed incomplete remissions. In Wagner-Jauregg's view, the European and American types of recurrent fever were too dangerous to consider as a possible treatment. The most effective method of treatment was induced malaria, particularly if it was combined with specific treatment with Salvarsan. ${ }^{72}$

In an appreciation of Wagner-Jauregg's work on the 90th anniversary of his birth, one of his former assistants $O$. Kauders (later head of the Clinic) spoke of the different methods examined, such as recurrent fever, rat-bite fever, and quartan malaria. He emphasized that Wagner-Jauregg did not make the tests himself, but let others carry them out so that the results would be unprejudiced. Wagner-Jauregg was always ready to abandon his own method in favour of a better one and was not blind to the faults of his achievement. He always insisted on controlled trials, which he termed Simultanmethode. ${ }^{73}$

In a report which he was invited to give at the Thirty-Eighth Congress of the German Society for Internal Medicine, in Wiesbaden in 1926, on the modern treatment of neuro-syphilis, ${ }^{74}$ he gave a detailed account of contemporary efforts at treating the disease and summarized his own researches over the previous years. He discussed experiments and facts which offered some explanation of the effect of treatment with malaria and recurrent fever. In experiments with rabbits by

\footnotetext{
69 Wagner-Jauregg, op. cit., note 67 above.

${ }^{70}$ Op. cit., note 65 above.

${ }^{71}$ W. M. McAlister, 'The results of the treatment of general paralysis by malaria', J. ment. Sci., 1925, 71: 236.

72 Wagner-Jauregg, op. cit., note 67 above.

73 O. Kauders, 'Julius Wagner von Jauregg', Wien. klin. Wschr., 1947, 59: 130-2.

74 Wagner-Jauregg, op. cit., note 67 above.
} 


\section{Magda Whitrow}

Weichbrodt and Jahnel, ${ }^{75}$ the spirochetes had disappeared from induced chancre as a result of high temperatures. Although the temperatures encountered in fever attacks of induced malaria were usually lower, Wagner-Jauregg claimed that they would still weaken the spirochetes. He believed that the fever produced by malaria should not be regarded as the principal cause of the therapeutic effect, because although the temperatures induced by recurrent fever or tuberculin were considerably lower, treatment with them had been effective. No spirochetes were found in the brains of paralytics who, before their deaths, underwent an illness accompanied by high fever.

In concluding his report Wagner-Jauregg emphasized that both malaria and the African recurrent fever had proved far the most effective methods, not only of treating GPI, but also in prophylactic treatment, that is in procuring negative results in the analysis of spinal fluid. As far as the treatment of tabes was concerned; these methods could also be recommended, with certain provisos.

Wagner-Jauregg embarked on his researches on the effect of fever on psychoses in 1887 and he first experimented on producing fever in $1888 / 89$. Thirty years were to elapse before, in 1917, he began his work on the use of malaria for treating paralytics. He had to wait many years for recognition of his achievements. In 1926 he was awarded the Erb Medal of the Society of German Neurologists and was made an Honorary Member of that Society. In 1927 the German Society for Psychiatry moved the venue of their annual meeting to Vienna in his honour and bestowed Honorary Membership on him, and in the same year he was awarded the Nobel Prize. His name had been put forward for the Prize as early as 1924, but the referee at the time, B. Gadelius, a Swedish professor of psychiatry, could not be persuaded to recommend the award to a "physician who injected malaria into a paralytic, because he was in his eyes a criminal". So Wagner-Jauregg had to wait until Gadelius retired. ${ }^{76}$

No one aside from Gadelius seems to have raised the ethical issue until the 1930s, when some American writers did so. There may still be some now who believe that it was wrong to induce a fever in someone who was already suffering from a fatal disease. However, there is no doubt that, at a time when GPI killed its victims within a few years, malaria therapy was the only hope for those afflicted. Although it was only 50 per cent successful and actually caused some deaths, it gave thousands of patients such marked improvement that they were able to resume a normal life.

\footnotetext{
${ }^{75}$ R. Weichbrodt and R. Jahnel, 'Einfluss hoher Körpertemperaturen auf die Spirochäten und Krankheitserscheinungen der Syphilis im Tierenexperiment', Dt. med. Wschr., 1919, 45(18): $483-4$.

76 Wagner-Jauregg, op. cit., note 1 above, p. 169.
} 